\title{
How to Handle Rejection?
}

Every time I was rejected for something good, I was actually being redirected to something better

Steve Maraboli, American Author and Motivational Speaker (1975-)

\subsection{What Are Reasons for the Outright Rejection of a Manuscript?}

The most important reason for immediate rejection is that the authors have not complied with all the necessary requirements of the journal. The submission of auxiliary documents that are necessary (ethics, conflict of interest) may have not been sent. The Editor in charge first looks at the title and the topic of the research $[1,2]$. When he feels that it may not have much interest to his readers, the paper can be directly sent back at this level.

There are many explanations for why the paper is rejected without a detailed peer reviewers' analysis. These include:

- The manuscript may be out of the scope of the journal and not appropriate for its audience.

- The paper may contain no hypothesis or a weak hypothesis.

- The manuscript may contain too much basic research which may not interest clinicians.

- The paper may have bad methodology, the sample size may not be adequate and the statistical analysis incorrect.

- There is a discordance of the affiliations between the authors and institutes.

- Conflict of interest not declared.

- Ethics committee permission not taken.

- No informed consent from subjects.

- Case reports not important enough for scientific literature. 
- The journal may have published a similar manuscript recently or is in the process of publishing one.

- There is plagiarism of language and ideas.

\subsection{What Are the Reasons for Rejection After the Peer Review Process?}

Only those manuscripts that survive the initial editorial inspection are sent for reviewers' opinions. This diminishes the load of papers on reviewers. Hence, expert commentators can focus and give time to do a detailed critical scrutiny of a goodquality paper [1-3]. The reasons for refusal to publish at this stage are as follows (Fig. 33.1):

- The scientific content lacks precision of thought.

- Data are inadequate, and the methodology section has irreparable deficits.

- Advice to authors has not been followed properly.

- The photographs are of low resolution, and tables are too complex and are not comprehensible.

- Discussion and conclusions do not answer the research question posed in the manuscript.

- There is an inconsistency between the statements made in the different sections of the paper.

- The reviewers feel that the authors have not edited the work enough to improve the presentation of the data.

- References are not according to the journal's style.

- There are mistakes in syntax and grammar.

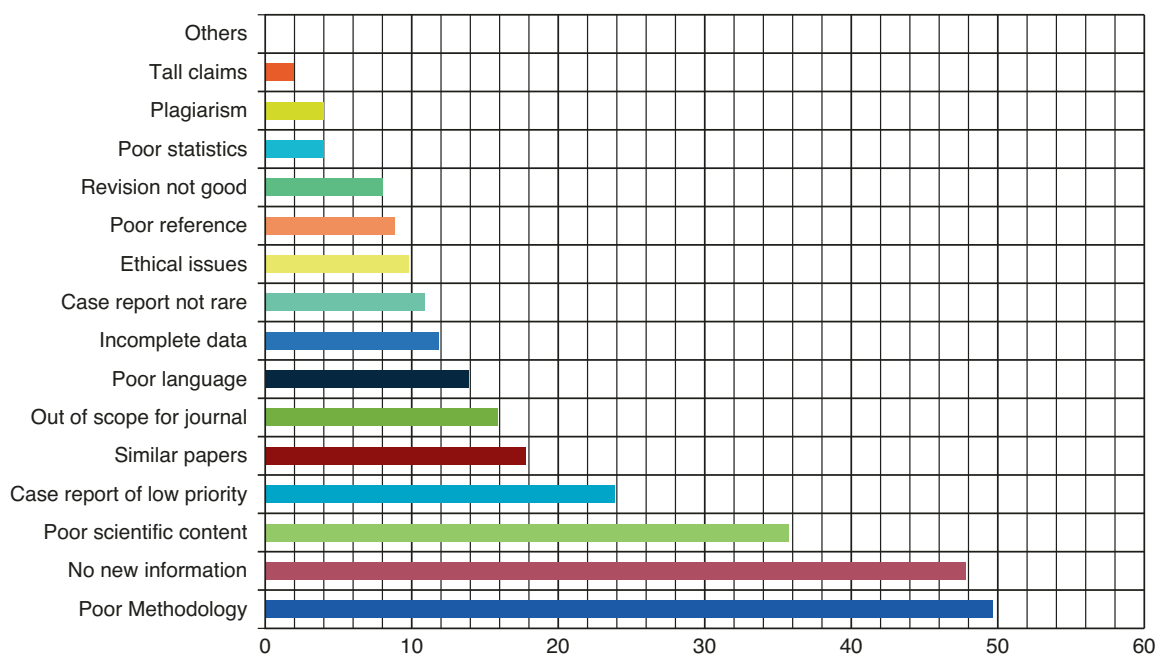

Fig. 33.1 An audit of reasons for rejection [1] 

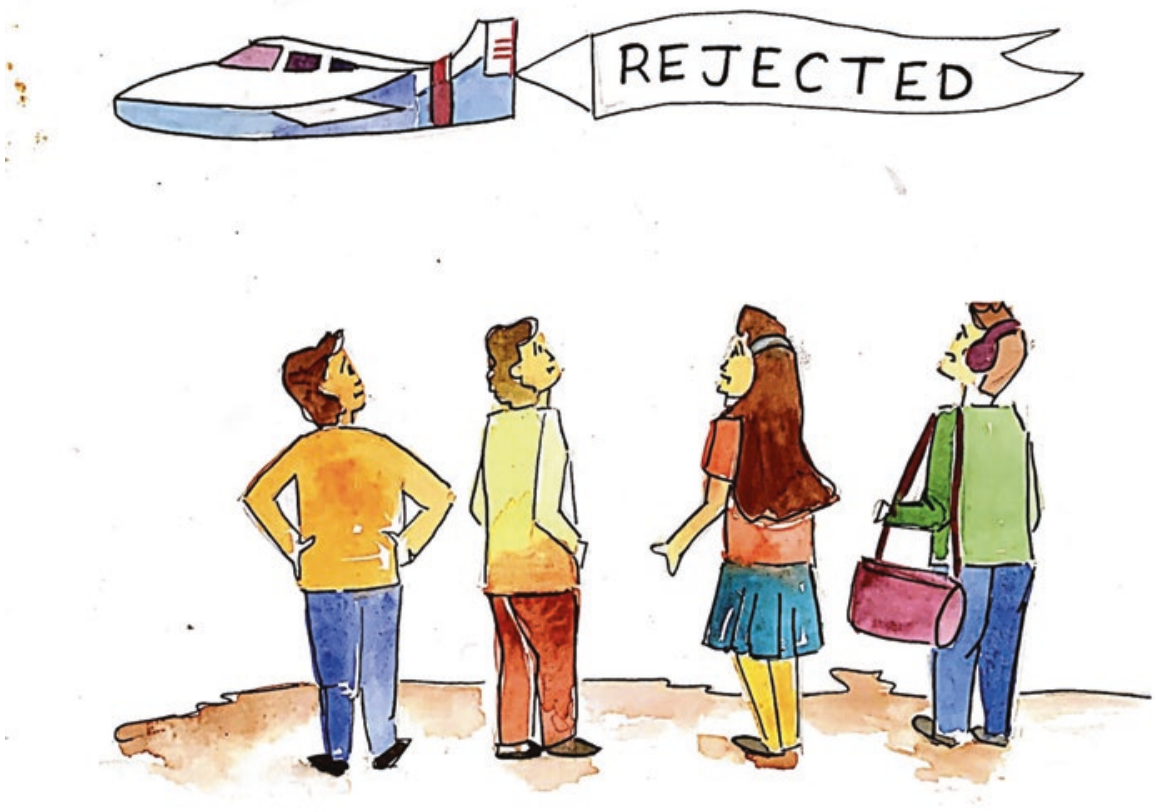

\subsection{What Should You Do After Rejection?}

The rejection rate of the leading journals varies from 80 to $95 \%$ [1]. It does not always mean that the manuscript is poorly written but that it is often not suitable for that journal. Look for the comments by the reviewers, improve the article and resubmit it to some other journal. If the reviewer has commented that the sample size is too small then you need to continue your work till you achieve an adequate number. Rejection is common so do not get disheartened and continue to improve the manuscript till you succeed in getting it accepted somewhere [4].

\subsection{What Are Few Tips for Coping with Rejection?}

- Do not feel dejected, it is a very common phenomenon.

- Read the comments of the referee and act on those.

- Resubmitting the paper to the same journal is usually not advisable.

- Check the formatting before submitting to a new journal.

- Match the paper with the journal's style.

- If the data is inadequate, continue the work till you reach an adequate sample size. 


\subsection{Conclusions}

- Rejection of an article is a very common phenomenon. It should be taken as a step towards improvement.

- Peer review of an article is done when the editors feel it is worth processing the article further.

- Resubmission should be done soon to another journal after incorporating all necessary suggestions for improvement.

\section{References}

1. Khadilkar SS. Rejection blues: why do research papers get rejected? J Obstet Gynaecol India. 2018;68:239-41.

2. Sullivan GM. What to do when your paper is rejected. J Grad Med Educ. 2015;7:1-3.

3. Dealing with Rejections - Three perspective that can help. Last accessed on 13th May2020. Available on https://www.servsig.org/wordpress/2019/11/this-can-be-of-no-interest-toanyone-dealing-with-rejections/.

4. Venketasubramanian R, Venketasubramanian N, Hennerici MG. How to handle a rejection. Cerebrovasc Dis. 2013;35:209-12.

Open Access This chapter is licensed under the terms of the Creative Commons Attribution 4.0 International License (http://creativecommons.org/licenses/by/4.0/), which permits use, sharing, adaptation, distribution and reproduction in any medium or format, as long as you give appropriate credit to the original author(s) and the source, provide a link to the Creative Commons license and indicate if changes were made.

The images or other third party material in this chapter are included in the chapter's Creative Commons license, unless indicated otherwise in a credit line to the material. If material is not included in the chapter's Creative Commons license and your intended use is not permitted by statutory regulation or exceeds the permitted use, you will need to obtain permission directly from the copyright holder. 